\title{
Incentives to using solar thermal energy in Taiwan
}

\author{
Keh-Chin Chang ${ }^{1}$, Wei-Min Lin ${ }^{2}$ and Kung-Ming Chung ${ }^{1 *}$
}

\begin{abstract}
A national subsidy program is one of the key elements for translating customer choice into a larger market share for renewable energies. Since solar water heaters (SWHs) are a cost-effective and mature technology, purchase-based subsidy programs have been sponsored by the Bureau of Energy, Ministry of Economic Affairs (BEMOEA) in Taiwan. The market of SWHs is associated with economic factors, population characteristics, degree of urbanization (available roof space), and climatic conditions. Regional programs have also affected the growth in sales. However, the penetration rates are still low, and the local market has changed little in recent years. Thus, the timing of the termination of the long-duration subsidy program is a subject of debate. In this study, a new scheme in the residential sector is proposed in the period of 2016 to 2019. In addition, small and medium enterprises (SMEs) make up the majority of Taiwanese companies. Most SMEs suffer from insufficient capital to support their commercial activities. To prompt solar thermal energy in the commercial sector, the energy service company (ESCO) business model can be adopted. The same feed-in tariffs for PV systems can be granted for SWHs and photovoltaic/thermal (PVT) systems with performance-based subsidies to end users or ESCOs.
\end{abstract}

Keywords: Solar thermal; Purchase-based subsidy; Performance-based subsidy

\section{Background}

Taiwan is an isolated island and depends exclusively on imported fossil fuels to fulfill its energy needs. In 2012, the total domestic energy consumption was $100,383 \times 10^{3}$ metric ton of oil equivalent, in which the energy use in the industrial and residential sectors accounted for $38.2 \%$ and $10.9 \%$, respectively (BEMOEA 2013). Moreover, utilization of renewable energy sources is critical for future socio-economic development. The Renewable Energy Development Bill was promulgated in 2010 by the government of Taiwan. The total capacity for power generation by renewable energy was 3,696.7 MW in 2012, including conventional hydropower (2,081.3 MW), wind power (571 MW), solar photovoltaic (222.4 MW), and biomass (822 MW). The accumulated area of solar collectors installed (solar water heaters (SWHs)) reached 2.27 million $\mathrm{m}^{2}$ (Chang et al. 2013a). Note that the renewable energy accounted for $1.89 \%$ of the total energy production in 2012 (BEMOEA 2013).

\footnotetext{
* Correspondence: kmchung@mail.ncku.edu.tw

${ }^{1}$ National Cheng Kung University, 2500 Section 1, Chung-Cheng South Road, Gueiren, Tainan City 711, Taiwan

Full list of author information is available at the end of the article
}

Taiwan is situated between latitude $22^{\circ}$ and $25^{\circ} \mathrm{N}$. Insolation ranges between 1,200 and $1,700 \mathrm{kWh} / \mathrm{m}^{2} /$ year. Solar thermal system has potential to help reduce domestic energy consumption of LPG, natural gas, and electricity. The area of solar collectors installed per annum $\Sigma A_{\mathrm{SC}}$ in Taiwan is shown in Figure 1. It can be seen that the number of SWHs $\left(\Sigma A_{\mathrm{SC}}<10,000 \mathrm{~m}^{2}\right)$ was quite limited until the mid 1980s. The significant increase in $\Sigma A_{\mathrm{SC}}$ after 1986 was due to the first subsidy program (1986 to 1991). The second and the third subsidy programs were initiated in 2000 and 2009, respectively. The accumulated area of solar collector installed in the period of 2000 to 2013 is approximately 1.5 million $\mathrm{m}^{2}$. An increase in sales resulted in a price reduction in the first four years (2000 to 2003). However, the price has changed little in recent years. In terms of unit price for an SWH, the value is approximately $10,500 \mathrm{NTD} / \mathrm{m}^{2}$ (Chang et al. 2013a). It has also been noted that the significant increase in the sales of SWHs in 2010 was due to a regional subsidy program by a local government (Lin et al. 2012). In Figure 1, it is also noted that the financial incentive might only be effective at the 


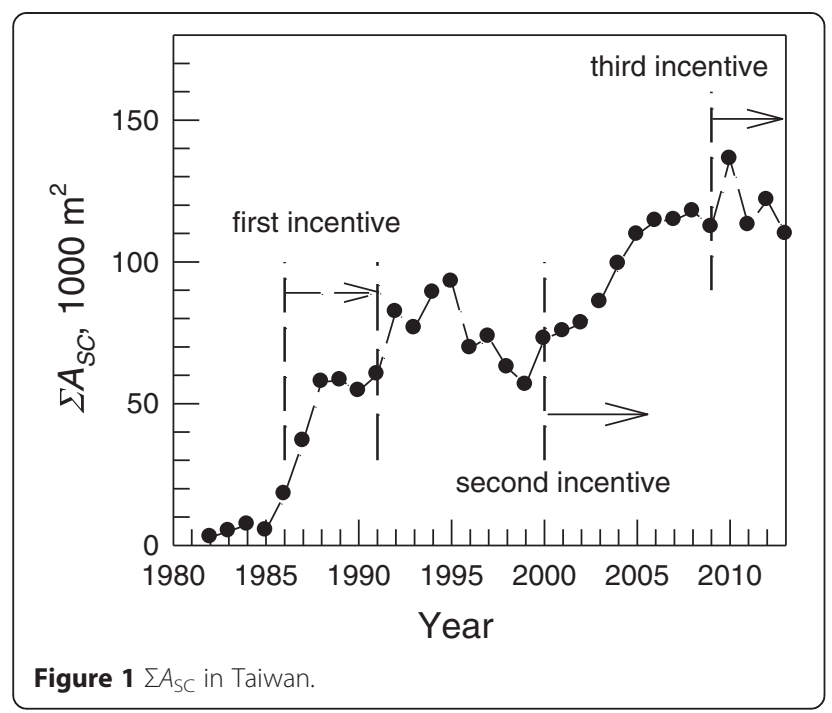

initial stage of each subsidy program (Chang et al. 2013b). Nevertheless, SWHs represent the most successful story of utilization of renewable energy in Taiwan.

Throughout the world, purchase-based subsidies, including direct subsidies (Germany and Austria), tax credits (France), or tax reduction (Greece), have been used for SWHs (Kalogirou 2003; Chandrasekar and Kandpal, 2005; Menanteau, 2007; Roulleau and Lloyd 2008; Pablo-Romero et al. 2013; Abu-Baker et al. 2014; Higgins et al. 2014). Stevanovic and Pucar (2012) noted that a $20 \%$ purchase-based subsidy is considered to be an appropriate subsidy level that makes SWHs financially more attractive in comparison with conventional electric or gas water heaters. However, Roulleau and Lloyd (2008) also pointed out that increasing the total number of systems may not result in real energy savings over the lifespan of the systems. In addition, performance-based subsidies have been distributed by some countries (e.g., UK, Sweden, Netherlands, and Victoria, Australia) (Roulleau and Lloyd 2008; Abu-Baker et al. 2014). However, it is more difficult to monitor thermal output of an SWH than the electrical energy output from a photovoltaic system.

The current purchase-based subsidy program in Taiwan has lasted for 14 years. However, the national subsidy program seems to have lost its momentum in expanding the market. Policy makers should evaluate the efficiency of this long-duration subsidy scheme. The present study is devoted to an extensive evaluation of the current subsidy program and the local SWHs market. New schemes are proposed to ensure a sustainable SWH industry in Taiwan and real energy savings, including a revised scheme in the residential sector and a performance-based one in the commercial sector.

\section{Methods- SWH market survey in Taiwan Subsidy programs}

Upfront subsidies (purchase-based subsidies) are the most widespread measure introduced by world governments. In Taiwan, the first subsidy program (1986 to 1991) was also based on the area of solar collector installed of an $\mathrm{SWH}$, $A_{\mathrm{SC}}$. A direct subsidy of $2,000 \mathrm{NTD} / \mathrm{m}^{2} \quad(1 \mathrm{USD} \approx 30$ NTD) was granted to 'the manufacturer' for an SWH with glazed flat-plate solar collectors or evacuated-tube solar collectors. With unglazed flat-plate solar collectors, the amount was 1,000 NTD/m². From 1991 to 1992, the subsidy was cut in half. Indeed, the end users were motivated by the financial incentive, and the $\Sigma A_{\mathrm{SC}}$ reached $60,000 \mathrm{~m}^{2}$ by the end of the program.

The second subsidy program was activated in 2000 . The Energy Research Center at National Cheng Kung University (ERC/NCKU) has been authorized by the Bureau of Energy, Ministry of Economic Affairs (BEMOEA) to organize an operation unit (Chang et al. 2011). A direct subsidy of $1,500 \mathrm{NTD} / \mathrm{m}^{2}$ was granted to 'the end user' purchasing a certified SWH with glazed flat-plate solar collectors or evacuated-tube solar collectors. The amount was $1,000 \mathrm{NTD} / \mathrm{m}^{2}$ for an $\mathrm{SWH}$ with unglazed flat-plate solar collectors. Note that the subsidy amount was double in remote islands. As shown in Figure 1, the $\Sigma A_{\mathrm{SC}}$ doubled from 1999 to 2006 . In the period of 2008 to 2009 , there was a decline in the $\Sigma A_{\mathrm{SC}}$. To disseminate SWHs, the direct subsidy has been increased 50\% from 2009 to present (the third subsidy program), e.g., 2,250 NTD $/ \mathrm{m}^{2}$ for glazed flat-plate solar collectors and evacuated-tube solar collectors.

\section{SWHs market (2001 to 2013)}

Chang et al. (2009) pointed out that the penetration rate and potential market of SWHs in Taiwan are associated with economic factors, population characteristics, degree of urbanization (available roof space) and climatic conditions. As a rule of thumb for system design of an $\mathrm{SWH}$ in the residential sector, the daily hot water consumption for each person corresponds to the hot water production of $A_{\mathrm{SC}} \approx 1 \mathrm{~m}^{2}$. During the last decade, the average $A_{\mathrm{SC}}$ with glazed flat-plate or evacuated-tube SWHs are approximately 5 and $3 \mathrm{~m}^{2}$, respectively. Further, the data of SWHs installed in terms of $A_{\mathrm{SC}}$ are shown in Table 1 . The $A_{\mathrm{SC}}$ of most systems $(98.24 \%)$ are less than $10 \mathrm{~m}^{2}$. There were only 154 systems installed with $A_{\mathrm{SC}} \geq 100 \mathrm{~m}^{2}$ for dormitories, swimming pools, manufacturing plants, and restaurants from 2001 to 2013 (Chang et al. 2013a).

\section{Results and discussion}

Financial incentives are definitely one of the key factors influencing dissemination of SWHs in many countries. Government grants have paid for up to $50 \%$ of the initial cost of SWHs (Stevanovic and Pucar 2012). However, 
Table $1 \mathrm{SWH}$ units installed in terms of $A_{\mathrm{SC}}\left(\mathrm{m}^{2}\right)$

\begin{tabular}{lllllll}
\hline Year & $<\mathbf{3}$ & $\mathbf{3}$ to $\mathbf{5}$ & $\mathbf{5}$ to $\mathbf{1 0}$ & $\mathbf{1 0}$ to $\mathbf{1 0 0}$ & $\mathbf{> 1 0 0}$ & Total \\
\hline 2001 & 1,192 & 5,504 & 5,880 & 277 & 8 & 12,861 \\
2002 & 1,979 & 6,236 & 6,342 & 321 & 6 & 14,884 \\
2003 & 2,114 & 7,310 & 7,176 & 352 & 4 & 16,956 \\
2004 & 2,983 & 9,220 & 9,409 & 349 & 9 & 21,970 \\
2005 & 3,227 & 9,688 & 9,581 & 326 & 8 & 22,830 \\
2006 & 3,988 & 10,468 & 9,913 & 303 & 12 & 24,684 \\
2007 & 4,174 & 11,134 & 8,980 & 354 & 4 & 24,646 \\
2008 & 4,004 & 11,397 & 8,665 & 439 & 12 & 24,517 \\
2009 & 3,270 & 8,874 & 7,660 & 388 & 18 & 20,210 \\
2010 & 3,536 & 11,077 & 11,408 & 580 & 16 & 26,617 \\
2011 & 3,082 & 10,157 & 9,794 & 394 & 28 & 23,455 \\
2012 & 2,714 & 11,251 & 10,059 & 354 & 15 & 24,393 \\
2013 & 2,272 & 9,775 & 9,282 & 336 & 12 & 21,675 \\
Sum & 38,535 & 122,091 & 114,149 & 4,773 & 152 & 279,698 \\
& $13.78 \%$ & $43.65 \%$ & $40.81 \%$ & $1.71 \%$ & $0.05 \%$ & \\
\hline
\end{tabular}

these discounted prices could lead to supply-side distortions. A possible negative impact on the sustainable development of the SWH industry is also expected. For instance, the total financial incentives offered by the Kinmen County (purchase-based subsidies, 2008 to 2010 ) and the BEMOEA in Taiwan approached the initial cost of an SWH (89\%). Therefore, it is considered that there were many over-designed systems installed, resulting in a mismatch between the production and the demand for hot water (Chang et al. 2011). In addition, the long subsidy program in Taiwan has lost its momentum in expanding the market. The distribution of capital subsidies could be put to better use. To maximize energy savings with solar energy, this study proposes a new scheme in the residential sector and performance-based incentives in the commercial sector as described below.

\section{A revised scheme in the residential sector}

With the well-organized efforts (financial incentives and research projects) taken by the BEMOEA, there is increasing public interest in SWHs. As shown in Figure 2, the accumulated area of solar collector installed increased significantly from the late 1980 s to $2000\left(\approx 1\right.$ million $\left.\mathrm{m}^{2}\right)$. Direct subsidies by the BEMOEA (2000 to present) had definitely positive effects on the dissemination of SWHs. In 2010, the accumulated area of solar collector installed reached 2 million $\mathrm{m}^{2}$. Further, with a service period for SWHs less than 15 years, the effective accumulated area of solar collector installed was approximately 1.5 million $\mathrm{m}^{2}$ (or 0.3 million systems in operation) in 2013.

Popularization of SWHs in Taiwan is strongly correlated with the demographic characteristics of households (Chang et al. 2009). From 2001 to 2011, the market share

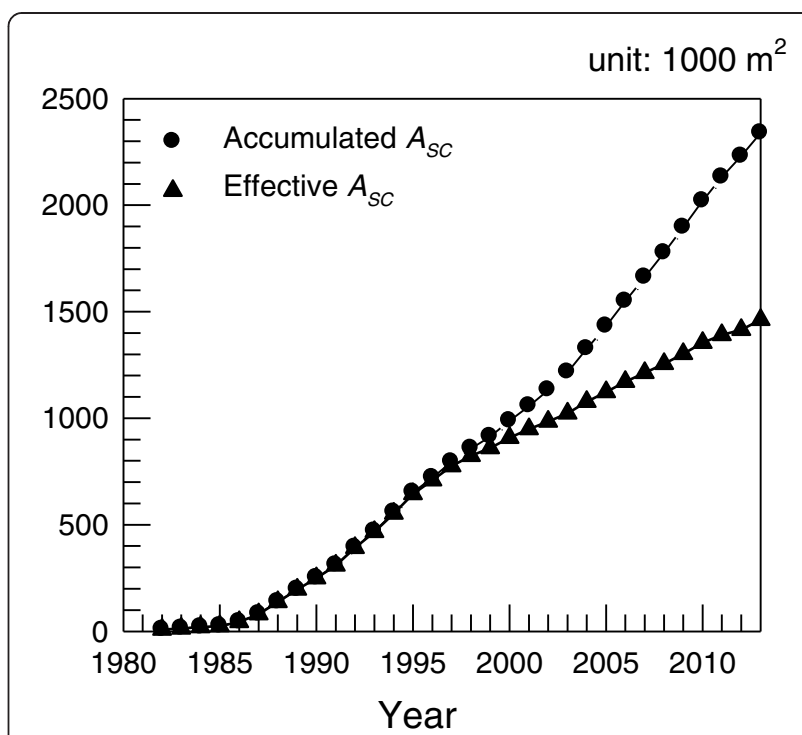

Figure 2 Accumulated and effective area of solar collector installed.

of SWHs for one- or two-person households contributed only $1.4 \%$. Stem families and some nucleus families have been more positive about installing SWHs (Lin et al. 2012). The households and the penetration rate of SWHs (SWHs/Households) with a service period of 15 years are shown in Figure 3. It can be seen that the number of households has doubled over the last three decades. As for the penetration rate, it increased significantly from 1985 to 2000, corresponding to an increase in the accumulated area of solar collector installed. With the second and the third subsidy programs, approximately 0.28 million SWHs were installed and the effective accumulated area of solar collector installed increased significantly. However, the penetration rate remained nearly constant (3.4\% to $3.67 \%)$. According to the data of the DGBAS (2013), household composition has become more simplified and the average size of households has decreased in Taiwan. In 2013, the

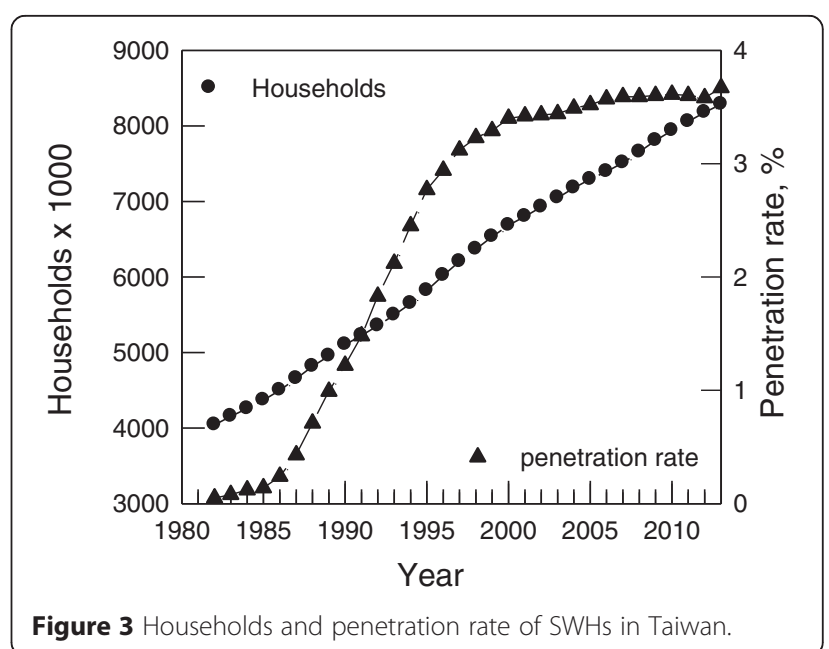


number of households with one or two persons is approximately four million. This partially explains the nearly frozen penetration rate during the last decade.

The timing of the termination of the current longduration subsidy program is a subject of debate. The major concern for policy makers is how to ensure a sustainable SWH industry upon the end of the financial incentive. Under the current subsidy, all installers or dealers (492 persons in 2013) must take some training courses and attain a certificate issued by the BEMOEA. Upon the termination of the current subsidy program, economies of scale (or local market) will be the key element to sustain this professional network to ensure the quality of products and post-installation service for the remaining portion of a system's technical life. When it comes to the end user, a field study (33,505 samples) was conducted by the ER/ NCKU from 2008 to 2013 (Chang et al. 2013a). It found that the public attitude towards SWHs is critical to motivate first-time users. The survey indicated that energy conservation $(68 \%)$ and safety (26\%) are of major concerns. Recommendation by local installers/dealers $(6 \%)$ or other SWH users (9\%) is another key factor. Nevertheless, many households have replaced old SWHs (22\%), of which the service periods of 10 to 15 years and over 15 years account for $22.8 \%$ and $58.0 \%$, respectively.

In the last decade, $55 \% \mathrm{SWHs}$ were installed in new buildings, of which the completion of housing construction was completed within 3 years. The subsidy programs and the status of new construction affect the local SWH market dramatically. As shown in Figure 4, the $\Sigma A_{\mathrm{SC}}$ is correlated reasonably well with the total floor area of occupancy permits, $\Sigma A_{\mathrm{op}}$, in which the ratio of $\Sigma A_{\mathrm{SC}} / \Sigma A_{\text {op }}$ increases significantly at the initial stage of each subsidy program and approaches some constant levels. The values are approximately $0.17 \%$ and $0.33 \%$ in

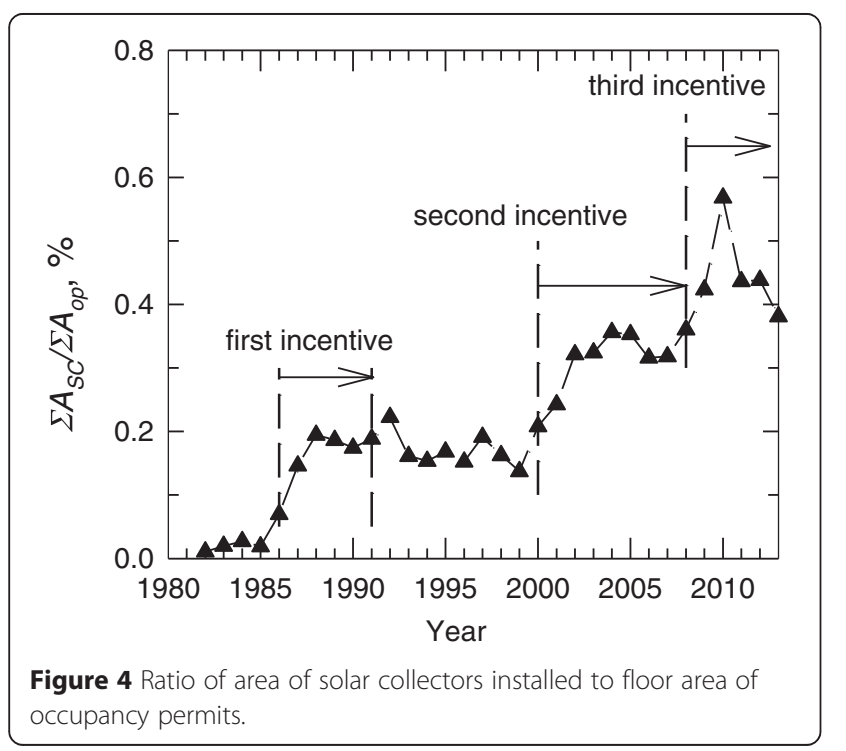

the periods of 1988 to 1999 (without financial incentives) and 2002 to 2007, respectively. In 2010, the peak value of $\Sigma A_{\mathrm{SC}} / \Sigma A_{\mathrm{op}}(=0.57 \%)$ corresponds to a regional subsidy program by a local government (Chang et al. 2011). It is also noted that the average value of $\Sigma A_{\mathrm{SC}}$ l $\Sigma A_{\text {op }}$ is $0.42 \%$ in the period of 2011 to 2013 . Therefore, upon the termination of the current subsidy program, it is possible to estimate the $\Sigma A_{\mathrm{SC}}$ installed in new buildings, e.g., $\Sigma A_{\mathrm{SC} \text {, new }}=\Sigma A_{\mathrm{op}} \times 0.42 \%$. It is also worth noting that more than $80 \%$ of end users have positive comments about system performance, and most of them (75\% of end users) are willing to purchase new SWH in the future. In particular, the piping and supporting structure account for approximately $10 \%$ of the initial cost. A lower initial cost can be expected for a replacement. With the service period of 15 years, $\Sigma A_{\mathrm{SC}}$ for the replacement can be estimated, e.g., $\Sigma A_{\mathrm{SC}}$, replacement, $2025=\Sigma A_{\mathrm{SC}}$, replacement, $2010 \times 75 \%$. Therefore, to ensure a sustainable SWH industry in Taiwan, two scenarios could be put into practice, of which the termination of the current subsidy program is in 2015 or 2019 . Note that the second one includes the deduction in direct subsidies (2016 to 2017, 2,000 NTD/m² 2018 to 2019, $\left.1,750 \mathrm{NTD} / \mathrm{m}^{2}\right)$. In this case, the ratio of the subsidy to the initial cost of an SWH for a four-person household would be approximately $12 \%$ in 2019 .

\section{A performance-based subsidy scheme in the commercial sector}

Timilsina et al. (2012) indicated that technological improvements and supportive government policies result in phenomenal growth in utilization of renewable energy. To promote domestic PV installation, the 'Million Rooftop PVs Project' was initiated by the BEMOEA in 2011. Targets of 1,020 and 3,100 MW of installed capacity have been set for 2020 and 2030, respectively. The project adopts a photovoltaic-energy service company (PV-ESCO) business model by providing capital financing to local system integrators and installers, gaining profits from reasonable whole-sale pricing. A feed-in tariff (FIT), ranging from $5.23 \mathrm{NTD} / \mathrm{kWh}$ (installed capacity $\geq 500 \mathrm{~kW}$ ) to 7.16 $\mathrm{NTD} / \mathrm{kWh}$ (installed capacity $=1$ to $10 \mathrm{~kW}$ ), is offered. Note that the retailed electricity price in the domestic sector was $2.97 \mathrm{NTD} / \mathrm{kWh}$ in 2012 BEMOEA, (2013).

According to the 'Measures for promoting solar water heaters' by the BEMOEA, the minimum thermal efficiency (ratio of useful heat absorbed by a solar water heater to incoming solar energy on the solar collector) for a certified SWH is 0.5. A field measurement of an SWH for dormitory application was conducted by Lin et al. (2012). Results indicated that the thermal efficiency of the system was higher than 0.3 only when the daily solar radiation per square meter exceeds $7 \mathrm{MJ} / \mathrm{m}^{2}$ (the Chinese National Standard 12558-B7277). Note that the maximum thermal efficiency was approximately 0.45 for 
the system. Since more than $98 \%$ of SWHs have been installed in the residential sector, system design of larger-scale SWHs is a critical issue for most installers. Therefore, the expected energy savings over the lifespan of a system cannot be realized under the present purchase-based subsidy program. To disseminate SWHs in the commercial sector (such as the food, agro, textiles, chemical, and beverage industries), an upgrading campaign is necessary within system design to facilitate effective energy saving. Nevertheless, Islam et al. (2013) demonstrated that the installation of an SWH with a large $A_{\mathrm{SC}}$ is more feasible compared to a small unit installed in terms of energy conservation and per unit energy cost over initial costs. Note that the initial cost per $A_{\mathrm{SC}}$ can be cut in half for a larger scale system in Taiwan (Chang et al. 2009).

For the field measurements by Lin et al. (2012), a solar meter, power meter, flow meter, and temperature sensors were employed to monitor thermal efficiency and actual thermal output of the system. For the FIT, the thermal output should be measured with correct quantity. An incentive should be paid for real energy savings, but not for heat which is vented into the atmosphere or where a heat requirement has been created artificially. A cost-effective heat meter and data logging are required. Details about choice and maintenance of metering were given by Crowther et al. (2010). Further, to see any meter reliability problems, a physical meter reading can be adopted to monitor thermal output from 2015 to 2019, followed by automatic meter reading through the mobile phone system. It should also be noted that the ER/NCKU is conducting field measurements of thermal output for two larger-scale SWHs. Data from the monitoring devices have been sampled and transmitted synchronously to the host computer at the ER/NCKU through the internet.

\section{Market of SWHs with the revised schemes}

Two scenarios in the residential sector were proposed in this study. Assuming a flat rate of construction for new buildings in the next decade, the $\Sigma A_{\mathrm{SC}}\left(=\Sigma A_{\mathrm{SC}}\right.$, new $+\Sigma A_{\mathrm{SC}}$, replacement) under both scenarios is shown in Figure 5. It can be seen that there is a big drop (30\% off) in the $\Sigma A_{\mathrm{SC}}$ upon the termination of the current subsidy program in 2015, followed by a slow recovery. Many installers and dealers could go out of business upon termination of the subsidy program, and the $\Sigma A_{\mathrm{SC}}$ would be less than 0.1 million $\mathrm{m}^{2}$ in 2025 . Under the second scenario, it can be seen that there will be a minor increase in the $\Sigma A_{\mathrm{SC}}$ from 2015 to 2019 and a $15 \%$ drop in 2020. In 2025 , the $\Sigma A_{\mathrm{SC}}$ will be $15 \%$ more than that under the first scenario. Therefore, the second scenario is strongly recommended to ensure a sustainable SWH industry in Taiwan, including a professional network of local installers/dealers.

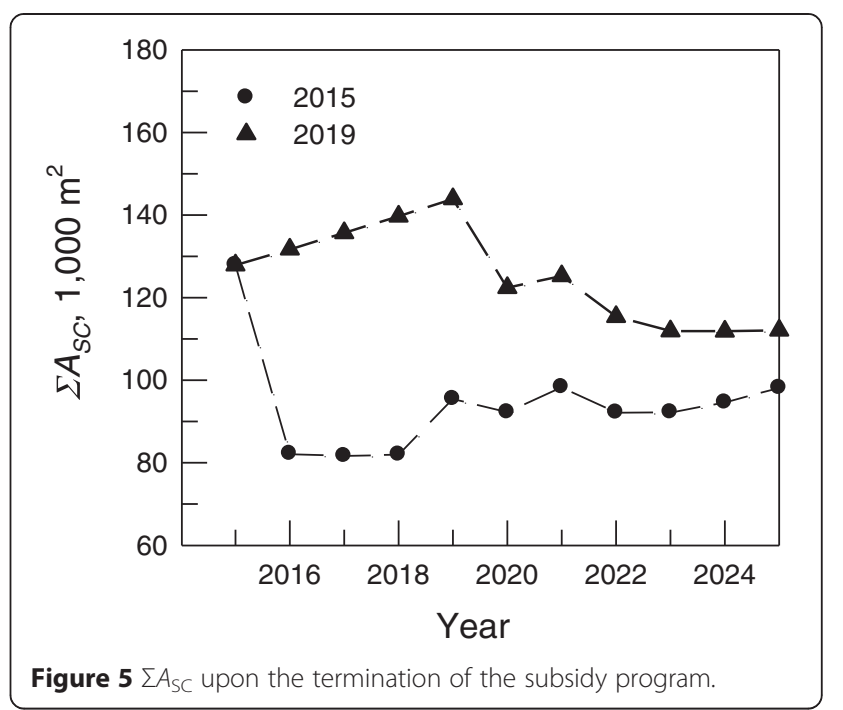

In the commercial sector, small and medium enterprises (SMEs) make up the majority of Taiwanese companies, comprising nearly $98 \%$ of the enterprises in Taiwan (SMEAMOEA 2013). Most SMEs suffer from insufficient capital to support their commercial activities. Therefore, economic viability is considered to be a key determinant of the dissemination of SWHs for industrial process heat applications. Based on the life cycle savings of SWHs, the payback period in terms of operation cost and effective energy savings over conventional heating fuels could be approximately 5 to 6 years (Pan et al. 2012). Thus, other than the direct subsidy to end users, the ESCO business model can be adopted by providing capital financing to ESCOs with SWHs installed in the commercial sector. In addition, a study that used a fixed FIT for SWHs in the UK was conducted by Abu-Baker et al. (2014). In terms of heating value of electricity $(3.60 \mathrm{MJ} / \mathrm{kWh})$, the same FIT for PV systems (NTD/kWh) can be granted for SWHs in terms of thermal output (NTD/kWth) in Taiwan. Upgrading system design or more innovative technologies for effective energy savings can be expected, resulting in a shorter payback period. Further, a significant amount of research and development work on photovoltaic/thermal (PVT) technology for both hot water and electricity production has been done since the 1970s (Chow 2010; Othman et al. 2013; Dubey and Tay 2013). Thermal and electrical energy can be produced by these systems at the same time. Therefore, this proposed that performancebased subsidy can also be applied for PVT systems and will help to match suitable products and systems with the best potential market.

\section{Conclusions}

Financial incentives by governments are definitely the key element for disseminating SWHs. However, the long-duration subsidy program in Taiwan has lost its 
momentum to expand the local market in recent years. To put capital subsidies to better use, a revised program is required. According to a general survey of end users, the service period of SWHs and the status of new construction, a revised subsidy program from 2016 to 2019 in the residential sector should aim to ensure a sustainable SWH industry in Taiwan and maintain a professional network to ensure the quality of products and post-installation service. In addition, few large-scale SWHs have been installed in the last decade. To boost the market, a performance-based subsidy program in the commercial sector (e.g., daily, textile and poultry industry) is proposed to maximize energy savings. The ESCO business model and FIT can be adopted for SWHs, as well as for PVT systems. To monitor thermal output, a cost-effective and reliable heat meter is a prerequisite. Meter reading is another major concern.

\section{Competing interests}

The authors declare that they have no competing interests.

\section{Authors' contributions}

KCC was the principal investigator and edited the manuscript. WML carried out the analysis of SWH market in Taiwan. KMC drafted the manuscript. All authors read and approved the final manuscript.

\section{Acknowledgements}

This work was supported by the Bureau of Energy, Ministry of Economic Affairs (102-D0303), Taiwan, Republic of China.

\section{Author details}

'National Cheng Kung University, 2500 Section 1, Chung-Cheng South Road, Gueiren, Tainan City 711, Taiwan. ${ }^{2}$ Tainan University of Technology, No. 529, Zhongzheng Road, Yongkang District, Tainan City 710, Taiwan.

Received: 20 October 2014 Accepted: 16 February 2015

Published online: 09 November 2015

\section{References}

Abu-Baker, ST, Muhammad-Sukki, F, Ramirez-Iniguez, R, Munir, AB, Yasin, SHM, Mallick, TK, McLennan, C, \& Rahim, RA. (2014). Financial analysis of the proposed renewable heat incentive for residential houses in the United Kingdom: a case on the solar thermal system. Energy Policy, 65, 552-561.

Bureau of Energy, (2013). 2012 energy statistical data book. Taipei, Taiwan, Republic of China: Ministry of Economic Affairs (BEMOEA).

Chandrasekar, S, \& Kandpal, TC. (2005). Effect of financial and fiscal incentives on the effective capital cost of solar energy technologies to the user. Solar Energy, 78, 147-156.

Chang, KC, Lin, WM, Lee, TS, \& Chung, KM. (2009). Local market of solar water heaters in Taiwan: review and perspectives. Renewable and Sustainable Energy Reviews, 13, 2605-2612.

Chang, KC, Lin, WM, Lee, TS, \& Chung, KM. (2011). Subsidy programs on diffusion of solar water heaters: Taiwan's experience. Energy Policy, 39(2), 563-567.

Chang, KC, Lee, TS, \& Chung, KM. (2013a). Solar water heating system promotion and subsidy. Taipei, Taiwan: BEMOEA, Republic of China.

Chang, KC, Lin, WM, \& Chung, KM. (2013b). Solar thermal market in Taiwan. Energy Policy, 55, 477-482.

Chow, TT. (2010). A review on photovoltaic/thermal hybrid solar technology. Applied Energy, 87, 365-379.

Crowther, M, Charlick, H, Bates, B, \& Green, R. (2010). Report to DECC on heat metering for the RHI. Gloucestershire United Kingdom: GASTEC at CRE Ltd, report GaC, 3875, 2010.

Directorate General of Budget Accounting and Statistics (DGBAS). (2013). Key economic and social indicators. Taipei, Taiwan: DGBAS, Republic of China.
Dubey, S, \& Tay, AAO. (2013). Testing of different types of photovoltaic-thermal (PVT) modules with heat flow pattern under tropical climatic conditions. Energy for Sustainable Development, 17, 1-12.

Higgins, A, McNamara, C, \& Foliente, G. (2014). Modeling future uptake of solar photovoltaics and water heaters under different government incentives. Technological Forecasting and Social Change, 83, 142-155.

Islam, MR, Sumath, K, \& Khan, SU. (2013). Solar water heating systems and their market trends. Renewable and Sustainable Energy Reviews, 17, 1-25.

Kalogirou, SA. (2003). The energy subsidization policies of Cyprus and their effect on renewable energy systems economics. Renewable Energy, 28, 1711-1728.

Lin, WM, Chang, KC, Liu, YM, \& Chung, KM. (2012). Field surveys of non-residential solar water heating systems in Taiwan. Energies, 5(2), 258-269.

Menanteau, P. (2007) Policy measures to support solar water heating: information, incentives and regulations. World Energy Council

Othman, MY, Ibrahim, A, Jin, GL, Ruslan, MH, \& Sopian, K. (2013). Photovoltaic-thermal (PV/T) technology - the future energy technology. Renewable Energy, 49, 171-174.

Pablo-Romero, MP, Sanchez-Braza, A, \& Perez, M. (2013). Incentives to promote solar thermal energy in Spain. Renewable and Sustainable Energy Reviews, 22, 198-208.

Pan, TC, Kao, JJ, \& Wong, CP. (2012). Effective solar radiation based benefit and cost analyses for solar water heater development in Taiwan. Renewable and Sustainable Energy Reviews, 16, 1874-1882.

Roulleau, T, \& Lloyd, CR. (2008). International policy issues regarding solar water heating, with a focus on New Zealand. Energy Policy, 36, 1843-1857.

Small and Medium Enterprise Administration, Ministry of Economic Affairs (SMEAMOEA). (2013). White paper on small and medium enterprises in Taiwan. Taipei, Taiwan: SMEAMOEA.

Stevanovic, S, \& Pucar, M. (2012). Financial measures Serbia should offer for solar water heating systems. Energy and Buildings, 54, 519-526.

Timilsina, GR, Lado Kurdgelashvilib, L, \& Narbel, PA. (2012). Solar energy: markets, economics and policies. Renewable and Sustainable Energy Reviews, 16, 449-465.

\section{Submit your manuscript to a SpringerOpen ${ }^{\odot}$ journal and benefit from:}

- Convenient online submission

Rigorous peer review

- Immediate publication on acceptance

- Open access: articles freely available online

- High visibility within the field

- Retaining the copyright to your article

Submit your next manuscript at $\gg$ springeropen.com 